\title{
MAGALHÃES, I. EU E TU: A CONSTITUIÇÃO DO SUJEITO NO DISCURSO MÉDICO. BRASÍLIA, THESAURUS, 2000, 181 PÁGS.
}

\author{
Resenhado por: Edna Cristina S. Santos
}

Eu e tu: a constituição do sujeito no discurso médico é um trabalho cuja proposta é a análise do discurso médico-pediátrico em hospitais públicos de Brasília, Distrito Federal, a fim de compreender esse tipo de discurso na sociedade brasileira, visto que se trata de um discurso assimétrico no qual a fala médica está carregada de ideologia própria. Pretende também examinar a construção da identidade de médicos, mães e crianças em textos de consultas gravadas, além de analisar os procedimentos discursivos que geram falhas interpretativas no momento da consulta. Para tal, fundamenta-se nas premissas teóricas da teoria social do discurso, segundo a proposta de análise crítica européia, e levanta reflexões sobre a linguagem em sua relação com disciplinas afins como a sociologia e a pragmática.

Esta obra, dividida em seis capítulos, apresenta no capítulo 1 a descrição da pesquisa e de seus participantes. Neste capítulo, a autora descreve como ocorre a interação entre médicos (detentores do saber), mães (criticadas pelos médicos de maneira desqualificada quanto à condução do tratamento) e crianças (que, em grande parte dos casos, são ignoradas pelos médicos, os quais não se preocupam em interagir com os pacientes) nas consultas pediátricas. Com base em questionário, elaborado para coletar depoimentos de pacientes adultos a respeito da consulta médica e o atendimento médico público à população, foi constatado que, segundo a opinião da maioria dos pacientes, há mais comunicação entre médicos e pacientes no setor privado que no setor público de saúde, visto que não há interesse dos médicos em buscar a comunicação efetiva com os pacientes do setor público, justificando tal postura devido à enorme quantidade de pacientes que aguardam atendimento nos hospitais públicos. Nos poucos casos em que os médicos interagiram com a criança, pôde-se perceber a intenção do médico em firmar um trato de cooperação com o paciente. 
Os médicos reconhecem o poder que exercem sobre o paciente de duas perspectivas: uma justifica o poder por uma questão de segurança; a outra contrapõe o poder médico à desconfiança dos pacientes, que rejeitam certos médicos numa postura defensiva contra a má conduta de muitos profissionais. Nesse aspecto, o poder dos médicos relaciona-se ao saber específico que detêm, pois, conforme o depoimento de uma mãe, ou os médicos solucionam o problema ou a criança morre.

No capítulo 2, são avaliados os métodos atuais de análise de discurso e as relações estabelecidas por pesquisadores com seus informantes, tendo como centro o conceito de ética. A autora argumenta a favor da pesquisa etnográfica-discursiva, ressaltando as contribuições que esses estudos podem oferecer para a formação de uma 'consciência lingüística crítica', que se refere a um conjunto de princípios do estudo da linguagem em contextos de relações de poder, visando à crítica de tais relações e a perspectiva de mudança discursiva e social.

No capítulo 3, Magalhães apresenta os conceitos principais da Teoria Social do Discurso ou Análise de Discurso Crítica (ADC), concebida por Norman Fairclough e influenciada por Michel Foucault e Antonio Gramsci, e da Escola Francesa de Análise do Discurso (ADF), inspirada nas idéias de Michel Pêcheux e influenciada pela idéias de Louis Althusser. A análise de discurso francesa se dedicou à análise do papel da linguagem e das representações imaginárias na reprodução da desigualdade entre as classes sociais, apoiada em três teorias: o materialismo histórico (teoria das formações sociais e das ideologias), a lingüística (teoria das estruturas e relações sintáticas e dos processos enunciativos) e o discurso (teoria da determinação histórica dos processos semânticos). Além disso, situou-se "no centro de preocupações de ordem histórica e teórica", ao produzir "estudos concretos que fizeram avançar a questão do sujeito, arrancando-o a uma visão psicologizante, por um lado, e à empiricidade imediata das situações de comunicação, por outro". A ADF enfatiza o sujeito numa rede de lugares constituídos pelo contexto sócio-histórico. Pêcheux formula uma noção de sujeito em que este tem a ilusão de ser a fonte do próprio dizer inconscientemente, sendo constitutivo da linguagem, e de forma consciente, quando o sujeito seleciona o que quer e o que não quer dizer. Para Fairclough, os sujeitos são moldados pelas posições de sujeito estabelecidas nos diversos discursos, 
sendo ao mesmo tempo capazes de agir como agentes sociais. Tal concepção de sujeito e de linguagem fundamenta o papel do discurso na reprodução social e mostra como o discurso pode contribuir para a transformação social. A ADC tem como objeto as relações de poder no discurso, bem como o modo como essas relações e a luta pelo poder moldam e transformam as práticas discursivas de uma sociedade ou instituição. Fairclough propõe uma concepção tridimensional do discurso constituída do texto, da prática discursiva e da prática social, reunindo assim três tradições analíticas: a análise lingüística e textual; a análise macrossociológica, relacionada às estruturas sociais; e a análise microssociológica, na qual a prática social é produzida e interpretada pelas pessoas com base em procedimentos de senso comum compartilhados. Buscando compreender a relação dialética entre discurso e estrutura social, a concepção de discurso de Fairclough está em conformidade com o debate desenvolvido pelas sociedades contemporâneas, que passam por profundas transformações, em torno de questões como identidades sociais e culturais, gênero social, ideologia, hegemonia e poder.

No capítulo 4, é feita a análise dos dados coletados sob a perspectiva da linguagem, da identidade e da ideologia de gênero no discurso médico-paciente. Nas consultas médicas analisadas, são observados aspectos lingüísticos que funcionam como pistas para a compreensão e interpretação da prática discursiva médico-paciente e codificam a representação da identidade dos médicos, associada ao conhecimento científico. A identidade do médico, representada pelos enunciados que o constituem em relação ao conhecimento acumulado historicamente pela instituição médica, associa-se ao seu comportamento que o revela como personagem dominante na interação, pois cabe ao médico fazer as perguntas, formular o diagnóstico, prescrever a dieta e testar o conhecimento dos residentes, momento em que a consulta médica transforma-se em um evento discursivo de letramento, estruturado em parte pela referência a um texto escrito, caracterizando-se como uma relação pedagógica em que é constituída a identidade dos aprendizes. As mães são representadas pelo discurso médico como sendo incultas e desprovidas de inteligência, além de receberem rótulos de hostis, calmas, culpadas, sensuais, nervosas, passivas, autoritárias, colaboradoras, atentas e alienadas. Ao classificarem o comportamento das mães, os médicos se posicionam como controladores da interação, incorrendo no que Bourdieu denomina de violência simbólica. 
Embora o tema das consultas pediátricas seja as crianças, elas falam muito pouco, sendo produzida, dessa forma, uma posição da criança como paciente. Além disso, os pediatras usam termos, para referirem-se às crianças, como aumentativos para os meninos e diminutivo para as meninas, de modo a reforçar e reproduzir assimetrias de poder entre homens e mulheres, constituindo a identidade de fragilidade para as meninas e identidade ligada à força física, à agressividade e ao poder para os meninos.

O capítulo 5 apresenta análise das falhas de interpretação que podem ocorrer no discurso médico-paciente em decorrência de procedimentos interpretativos diferenciados entre médicos e pacientes, indicando a racionalidade científica de um lado e a experiência de senso-comum, de outro. Os problemas interpretativos analisados referem-se à violação de determinados princípios, que geram sentidos inesperados, com a finalidade de controlar a interpretação do(a) interlocutor(a), provocando assim divergência em relação aos procedimentos interpretativos dos sujeitos. Como a aquisição de conhecimento é socialmente diferenciada, os procedimentos de interpretação variam entre os sujeitos, desencadeando uma leitura heterogênea dos textos. Por exemplo, os médicos detêm recursos interpretativos especializados que os diferenciam e caracterizam como pertencentes à instituição médica. Por isso, assumem uma identidade que lhes permite falar de um lugar social que, por sua vez, representa um saber subjacente ao poder terapêutico de sua fala. Por outro lado, na interação estabelecem um lugar para as mães e as crianças, considerando que cabe à mãe uma conduta benéfica à saúde da criança. A assimetria se verifica também quanto às formas lingüísticas usadas para a mãe da criança, que representam a mulher de forma rígida, autoritária e conservadora. O mero uso de diminutivo para mães e crianças não significa um cuidado real com a saúde dos pacientes, podendo indicar uma relação paternalista que deve ser evitada, pois oculta profunda assimetria e distância social. Tal processo de mudança discursiva precisa ser reorientado, objetivando a preservação da saúde dos pacientes. O cuidado com a saúde e a vida exige mudanças efetivas nas relações entre os membros da comunidade discursiva médica, principalmente na relação com os pacientes.

O capítulo 6 apresenta um resumo de rearticulações e mudanças constatadas na ordem de discurso médica baseadas nos conceitos de comunida- 
de discursiva, que se refere aos grupos e organizações em que os textos são produzidos, e mudança discursiva. O discurso médico-paciente encontra-se em processo de mudança, em virtude de transformações relacionadas às rearticulações interdiscursivas entre o público e o privado. Trata-se de tendências gerais de transformação que afetam a ordem discursiva societária, como, por exemplo, a democratização do discurso (Fairclough).

Magalhães chama a atenção para dois aspectos centrais em sua pesquisa: os procedimentos que originam as falhas de interpretação entre os médicos e as mães nas consultas pediátricas, bem como os modos como se instauram as identidades dos envolvidos na interação médico-paciente.

As dificuldades de interpretação podem ser provocadas pela violação ou ruptura de princípios conversacionais que regem a comunicação como o Princípio Cooperativo de Grice, segundo o qual o falante deve fazer sua contribuição tal como é exigida pelo contexto situacional, no momento em que ocorre, de acordo com a finalidade do intercâmbio conversacional. No processo da interação comunicativa, freqüentemente as pessoas transmitem muito mais do que suas palavras explicitam, cabendo aos seus ouvintes buscar os sentidos adicionais veiculados por seus enunciados. Com o objetivo de distinguir entre o que os falantes dizem do que realmente pretendem significar, Grice desenvolveu o conceito de implicatura para mostrar como as pessoas usam a língua, sugerindo que há suposições, por parte dos interlocutores, que podem ser formuladas como diretrizes que contribuem para uma conversação eficiente e cooperativa. Tais suposições são construídas porque as 'molduras' são ativadas. Moldura é um conceito que se refere à representação do conhecimento através de estereótipos sobre um tópico, caracterizando eventos, posições de sujeito, seres inanimados e processos. Como a ativação de molduras ocorre diversamente de sujeito para sujeito, em virtude de suas diferentes histórias interacionais e posições sociais ocupadas na prática discursiva, a sua relação com pistas textuais provoca a heterogeneidade de sentidos, a qual gera falhas na interpretação.

No entanto, esta pesquisa mostrou que há situações na consulta pediátrica em que médicos e mães violam máximas conversacionais, seja porque os médicos não fornecem as explicações necessárias ao tratamento da criança de forma adequada, seja porque as mães introduzem uma nova moldura, que é incompatível com os valores médicos científicos, tais como 
o uso de tratamento alternativo baseado em infusões de raízes e a prática de rezas e benzeções. Em termos societários, as diferenças interpretativas no discurso médico-paciente se revelam como ordens de discurso em confronto. Isso ocorre porque o poder institucional médico requer o cumprimento de suas prescrições pela mãe da criança, que, por sua vez, cumpre horário de trabalho e por isso fica muitas vezes sem condições de cuidar da criança satisfatoriamente, segundo a visão dos médicos. A voz da mãe baseia-se na experiência do senso comum; a voz do médico representa a autoridade do conhecimento científico e tecnológico e, por isso, dispensa explicações, caracterizando-se como um sistema impermeável ao diálogo e à negociação. Além disso, apresenta elementos de uma ordem discursiva discriminatória em relação à mulher, que se mantém implícita à produção e interpretação do discurso na sociedade brasileira.

Outra questão importante sobre a qual se deve refletir é a ocorrência de violência simbólica contra a mulher recorrente no discurso médico. Dada a relação de poder assimétrica que se estabelece no contexto de interação médico-paciente, mais precisamente entre médico pediatra e mãe da criança, constata-se que médicos e médicas se referem às mães de maneira discriminatória com uso de expressões pejorativas e desqualificadoras, em clara demonstração de falta de consideração com as mães ("essa mãe é uma obcecada total certo?" p. 112; "existem mães de vários tipos (...) existem mães aqui que são totalmente alienadas”pp. 129/130; “já viu vaca dar mamadeira pro boizinho?” p. 160). Segundo Bourdieu, em seu livro A dominação masculina, "a violência simbólica se institui por intermédio da adesão que o dominado não pode deixar de conceder ao dominante (e, portanto, à dominação) quando ele não dispõe (...) mais que instrumentos de conhecimento que ambos têm em comum e que, não sendo mais que a forma incorporada da relação de dominação, fazem esta relação ser vista como natural...". Por que as mães das crianças consultadas aceitam esse tratamento imposto pela instituição médica? Porque inconscientemente reproduzem estruturas de dominação, construídas incessantemente por instituições como família, religião, escola, Estado sob a forma de esquemas de percepção e de disposições, como admiração, respeito, amor, assim naturalizando as relações de dominação. Além disso, visto que as relações de comunicação constituem-se em relações de poder que dependem do poder simbólico acumulado por agentes e instituições envolvidos 
nessas relações, os sistemas simbólicos contribuem para assegurar a dominação de uma classe sobre a outra, gerando a violência simbólica, que contribui para a "domesticação dos dominados". (Bourdieu). A ruptura dessa relação de cumplicidade das vítimas da dominação simbólica só será possível com a transformação das condições sociais de produção das tendências da ótica dominante adotada pelos dominados. Nesse aspecto, esta pesquisa oferece valiosa contribuição àqueles que pretendem assumir um papel nas lutas políticas contra todas as formas de dominação, especialmente contra as mulheres, vítimas da desigualdade de gênero.

Eu e tu: a constituição do sujeito no discurso médico é uma obra de grande interesse para aqueles que desenvolvem pesquisa na área de análise lingüística do discurso, além de apontar perspectivas de mudança na linguagem e na prática social médica numa sociedade marcada profundamente por relações sociais desiguais e autoritárias, que nada contribuem para melhorar a vida e amenizar o sofrimento das populações de baixa renda, usuárias do sistema público de saúde. Nesse sentido, Gomes (2001: 168) mostra que o desenvolvimento de uma consciência lingüística crítica é fundamental para que os falantes percebam o modo como as relações de poder e as ideologias moldam as relações sociais e a constituição das identidades, a fim de lutarem por uma posição favorável no discurso.

\section{REFERÊNCIAS BIBLIOGRÁfICAS}

Bakhtin, M. Marxismo e filosofia da linguagem. 6a ed. São Paulo: Hucitec, 1992. Bourdieu, P. O poder simbólico. Trad. F. Tomaz. $4^{\text {a }}$ ed. Rio de Janeiro: Bertrand Brasil, 2001.

Fairclough, N. Discurso e mudança social. Coord. trad I. Magalhães. Brasília: Editora Universidade de Brasília, 2001.

Gomes, C. H. F. de Lima. Resenha de Eu e tu: a constituição do sujeito no discurso médico. Cadernos de Linguagem e Sociedade, Brasilia: Thesaurus, Vol. 5, 2001.

Mey, J. L. Pragmatics: an introduction. $2^{a}$ ed. Malden, Massachusetts: Blackwell, 2001.

Thomas, J. Meaning in interaction: an introduction to pragmatics. Nova York: Longman, 1995. 